\title{
Histomorphometric analysis of the repair process of autogenous bone grafts fixed at rat calvaria with cyanoacrylate
}

\author{
Jônatas Caldeira ESTEVES ${ }^{1}$, Albanir Gabriel BORRASCA ${ }^{2}$, Alessandra Marcondes ARANEGA ${ }^{3}$, Idelmo Rangel \\ GARCIA JUNIOR ${ }^{3}$, Osvaldo MAGRO FILHO ${ }^{3}$
}

\begin{abstract}
1- DDS, MSc, Master in Oral and Maxillofacial Surgery, PhD student in Implantology, Araraquara Dental School, UNESP - Univ. Estadual Paulista, Araraquara, SP, Brazil.

2- DDs, MSc in Oral and Maxillofacial Surgery, PhD student in Oral and Maxillofacial Surgery, Araraquara Dental School, UNESP - Univ. Estadual Paulista, Araraquara, SP, Brazil.

3- DDS, MSc, PhD, Assistant Professor, Division of Oral and Maxillofacial Surgery, Department of Diagnostics and Surgery, Araraquara Dental School, UNESP - Univ. Estadual Paulista, Araraquara, SP, Brazil.
\end{abstract}

Corresponding address: Jônatas Caldeira Esteves - Rua Humaitá, 1680, $2^{0}$ andar, Departamento de Periodontia - Centro - $14801-903$ - Araraquara-SP Phone: 5516 8839-0803 - Fax: 5516 3301-6369 - e-mail: jonatasce@hotmail.com

Received: October 26, 2009 - Modification: May 02, 2010 - Accepted: October 26, 2010

\section{ABSTRACT}

\begin{abstract}
O bjective: The purpose of this study was to perform histological and histometric analyses of the repair process of autogenous bone grafts fixed at rat calvaria with ethyl-cyanoacrylate adhesive. Material and Methods: Thirty-two rats were divided into two groups $(n=16)$, Group I - Control and Group II - Adhesive. Osteotomies were made at the right parietal bone for graft obtainment using a 4-mm-diameter trephine drill. Then, the bone segments were fixed with the adhesive in the parietal region of the opposite side to the donor site. After 10 and 30 days, 8 animals of each group were euthanized and the calvarias were laboratorially processed for obtaining hematoxylin and eosin-stained slides for histological and histometric analyses. Results: An intense inflammatory reaction was observed at the 10-day period. At 30 days, this reaction was less intense, despite the presence of adhesive at the recipient-site/graft interface. Graft incorporation to the recipient site was observed only at the control group, which maintained the highest graft size at 10 and 30 days. Conclusions: Although the fragment was stable, the presence of adhesive in Group II did not allow graft incorporation to the recipient site, determining a localized, discrete and persistent inflammatory reaction.
\end{abstract}

Key words: Tissue adhesives. Cyanoacrylates. Bone transplantation.

\section{INTRODUCTION}

Autogenous grafting is the most commonly used surgical procedure for bone reconstruction due to its advantages in comparison with other graft materials, such as biocompatibility and bone regeneration potential ${ }^{4}$. Several possibilities are reported by the literature for atrophic jaws reconstruction, and among these solutions it is possible to cite intra and extra-oral autogenous grafts, allografts, alloplastic and xenogenic grafts, with or without the use of membranes for guided bone regeneration ${ }^{19,20}$.

Autogenous bone grafts are considered the most suitable for the reconstruction of defects at oral and maxillofacial regions, mainly due to their characteristics of osteoinduction and osteoconduction. It is the only type of graft that provides live immunocompatible bone cells, essential to the stage I of osteogenesis. This makes this type of graft more advantageous, since the higher the amount of transplanted living cells, the higher the possibility of new bone formation ${ }^{4,5,20}$.

Graft fixation is a fundamental procedure for the normal process of bone regeneration ${ }^{17}$. In the last decade, plates and screws, represented by metallic and biodegradable materials, have been used preferably for obtaining graft stability as well as for fixation of fractures of the whole craniofacial bone. This is due to the fact that these materials provide a rigid fixation with tridimensional control of the bone 
position $^{1,27}$. On the other hand, disadvantages such as inflammatory reactions, bone displacement and technical difficulty have guided medical and dental researchers to the search for an alternative method for graft fixation, and, in this field, tissue adhesives are a resource potentially capable of providing stability for the healing process ${ }^{12}$.

Tissue adhesives based on cyanoacrylate (CA) are substances that have been successfully employed for skin laceration synthesis and surgical incisions $6,10,13,22,25$, as well as for the stabilization of thin bone fragments in orbital fractures ${ }^{13}$ and osteochondral fractures ${ }^{26}$. The most interesting properties of the adhesives are their rapid polymerization, strong adhesion to the surfaces where they are applied, biocompatibility ${ }^{2,8,12}$, bacteriostatic ${ }^{15,22}$ and hemostatic actions ${ }^{18}$, besides being a quick and atraumatic fixation method $3,10,21$.

Ethyl-CA, which is a short chain CA, was one of the first adhesives to be tested for medical use, presenting excellent adhesive strength ${ }^{11}$. However, its apparent toxicity to soft tissues conducted the researches for adhesives of longer chain, such as butyl and octyl-CA, which present higher biocompatibility 9 .

In spite of these findings, the adhesive capacity of ethyl-CA has still been tested for biological use in bone tissue fixation, with satisfactory results ${ }^{3,14,16,24}$. Generally, few studies have investigated the CA behavior on mineralized tissues fixation. The purpose of this study was to perform histological and histometric analyses of the repair process of autogenous bone grafts fixed at rat calvaria with ethyl-CA adhesive

\section{MATERIAL AND METHODS}

This study was approved by the institutional Research Ethics Committee (Protocol \#2008005587). Thirty-two male adult rats were used (Rattus norvegicus albinus, Wistar) with mean weight of $250 \mathrm{~g}$, divided into 2 experimental groups of 16 animals each: Group I - Control and Group II - Adhesive. During the whole experiment, the animals were kept in cages at the Vivarium of the Department of Surgery and Integrated Clinics and fed solid animal chow (Guabi Nutrilabor ${ }^{\circledR}$, Mogiana Alimentos, São Paulo, SP, Brazil) and water ad libitum, except in the fasting period (14-16 hours) that preceded the surgical procedure, in which they received only water.

After anesthesia with intramuscular xylazine hydrochloride $(0.2 \mathrm{~mL} / 250 \mathrm{~g})$ (Xilazin ${ }^{\circledR}$, Syntec do Brasil Ltda, Cotia, SP, Brazil) and ketamine hydrochloride (Cetamin ${ }^{\circledR}$, Syntec do Brasil Ltda, Cotia, SP, Brazil) $(0.1 \mathrm{~mL} / 250 \mathrm{~g})$, shaving and antisepsis were accomplished with $10 \%$ PVP-I in the frontoparietal region. The animals received an approximately 20-mm-wide mid-longitudinal incision in the scalp over the sagittal calvarial suture, followed by soft-tissue dissection, exposing the parietal bones. In each animal, a rounded osteotomy was made in the right parietal bone with a 4-mmdiameter trephine bur at low speed under constant saline irrigation to obtain a rounded bone fragment, preserving the integrity of the dura mater and brain. The defect was kept with the cavity covered by blood clot and was not examined. In the left side, at the site that would receive the graft, the parietal bone was decorticalized with a \#8 spherical bur at low speed. In Group I, the graft was only positioned at the recipient site, without any type of fixation material. In Group II, the graft was fixed with ethyl-CA adhesive (Super Bonder ${ }^{\circledR}$; Loctite-Henkel, Itapevi, SP, Brazil) applied with a microbrush. The flap was repositioned and sutured with continuous spiraled suture using Mononylon 5-0 (Mononylon ${ }^{\circledR}$, J\&J Ethicon, São José dos Campos, SP, Brazil).

The animals were euthanized by anesthetic overdose at 10 and 30 postoperative days ( 8 animals/period). The calvaria were removed and the left parietal bones were separated, preserving the supraperiosteal soft tissues. The pieces were fixed in $10 \%$ formaldehyde and subjected to routine laboratorial processing. Six-micrometer-thick cross sections were obtained and stained with hematoxylin and eosin for histological and histometric analyses.

In the histological (qualitative) analysis, the graft/recipient site interface, the presence of the following items was assessed: adhesive fragments, inflammatory infiltrate, fibroblastic proliferation and new bone and capillary formation, in superficial and deep tissues.

In the histometric (quantitative) analysis, the slides were examined in an optical microscope (Aristoplan-Leitz ${ }^{\circledR}$, Leica, Wetzlar, Hesse, Germany) at 2.5x magnification, through a camera (Axio Cam MRc5 ${ }^{\circledR}$, Zeiss, Santo Amaro, SP, Brazil) connected to a computer. Using the AxioVision 4.5 software, the images were converted into digital "TIF" files, standardizing the height, width and number of pixels per inch. The bone graft size at 10 and 30 days was quantified in pixels, using the Imagelab 2000 software (Diracon Bio Informática Ltda, Vargem Grande do Sul. SP, Brazil). The evaluation was performed by a single trained examiner and the measurements were done at three different moments, with an interval of 1 week between the evaluations. The mean of these three values was assigned to each slide, and the value was used for statistical analysis.

Statistical analysis was accomplished with GMC 9 software (Statistical software created by Prof. Geraldo Maia - FORP-USP). Initially, data were submitted to normal curve adherence test, which showed a non-parametric behavior. Thus, Kruskal- 
Wallis test was used to compare the data at 10 and 30 days. The Mann-Whitney test was used for individual comparisons $(p<0.05)$.

\section{RESULTS}

All animals tolerated well the experimental procedures in such a way that, at 10 days after postoperatively, the soft tissues handled during the surgical procedures were already healed, with an aspect of normality and without signs of infection or wound dehiscence.

\section{Histological results \\ 10 days - Group I}

Superficially, the periosteum presented hyperplasia with a discrete inflammatory infiltrate. Underneath, the graft was observed, with most of its osteocyte lacunae filled by osteocytes. At the interface between the graft and the recipient site, it was possible to observe a thin layer of compact fibrous connective tissue and areas of bone remodeling both at the graft and the parietal bone. At the peripheral regions, it was observed areas with initial new bone formation (Figure 1 ).

\section{0 days - Group II}

Superficially, it was possible to observe a thin fibrous capsule covering the bone graft. In most specimens, a predominance of lymphocytes together with a large number of neutrophils was observed. Adjacent to the fibrous capsule it was possible to notice the bone graft with its osteocyte lacunae containing basophilic nucleus. Several bone lacunae were found into the grafts containing multinucleate cells, and, in most of the specimens, a large number of neutrophils. Deeply and adjacent to the graft, fragments of CA were observed filling the space between the graft and the recipient site. Adjacent to the bone surface of the recipient site, there were several resorption areas with a large number of osteoclastic-type multinucleate cells. A large number of lymphocytes and neutrophils were observed into the medullar spaces of the bone tissue. Few fibroblasts could be identified, with a predominance of resorption areas concerning new bone formation areas. Discrete areas of new bone formation could be seen in the recipient site. It was still possible to observe the absence of a bone union between the bone graft and the recipient site (Figure 2 ).

\section{0 days - Group I}

At 30 days, the periosteum layer over the graft showed no signs of hyperplasia, and presented a discrete inflammatory infiltrate. Bone graft was attached to the recipient site through newly formed bone tissue at the interface region. In several specimens, this new bone formation occurs only

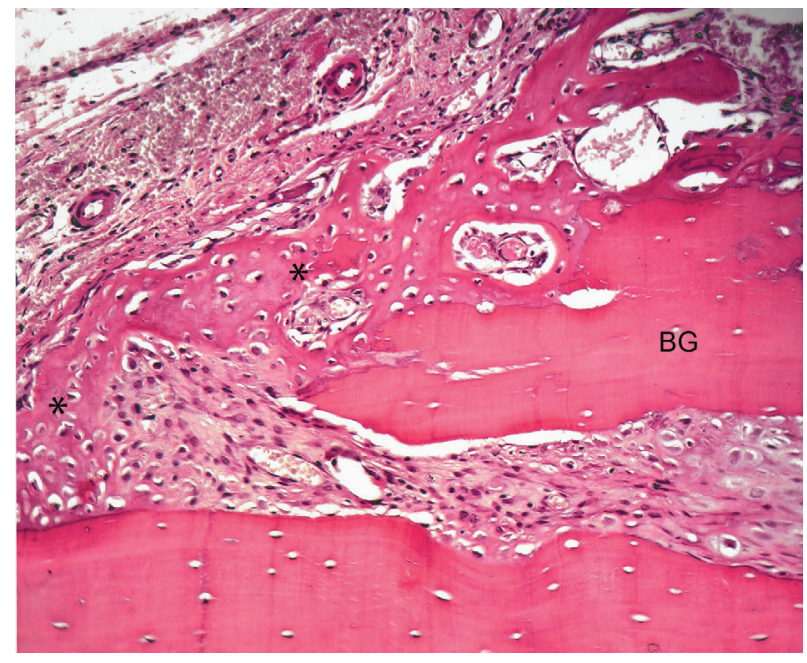

Figure 1- Group I - 10 days: Peripheral region of the graft. New bone formation, with primary bone tissue (asterisks), from the graft fragment (bone graft - BG) and parietal bone (hematoxylin-eosin - Original 160x)

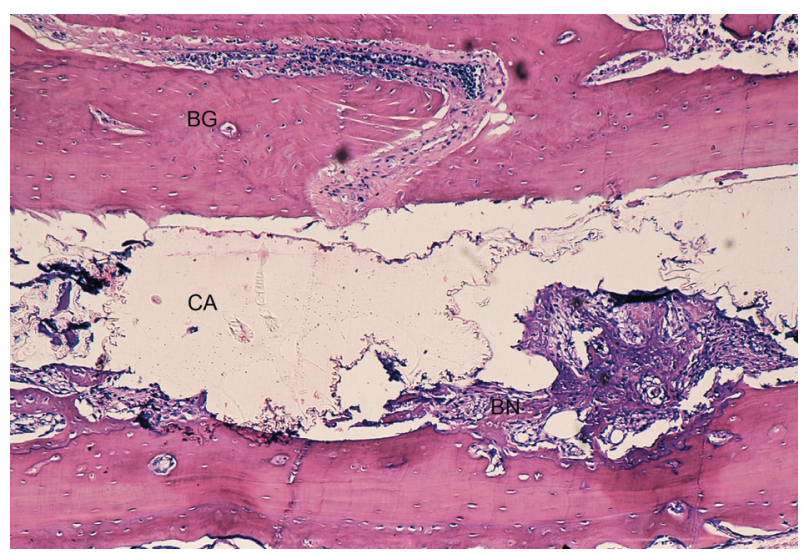

Figure 2- Group II - 10 days: Bone graft (BG) with osteocyte lacunae containing basophilic nucleus. Fragments of cyanoacrylate $(C A)$ are observed filling the space between the bone graft and the recipient site and discrete areas of new bone formation (BN) can be observed in the recipient site (hematoxylin-eosin - Original 63x)

at the central third of the graft, and their margins remained joined to the donor area by a compact connective tissue (Figure 3 ). The graft had an aspect of mature bone, well vascularized and with osteocyte lacunae filled by osteocytes in Havers systems.

\section{0 days - Group II}

In all specimens, a fibrous capsule covered the bone graft. Underneath the fibrous capsule, graft presents some areas of bone resorption in its external surface, with some osteoclastic-type multinucleate cells. These resorptions could also be observed into the bone fragment. In the graft proximal areas, in some specimens, a bone union with the recipient site was observed; however, 


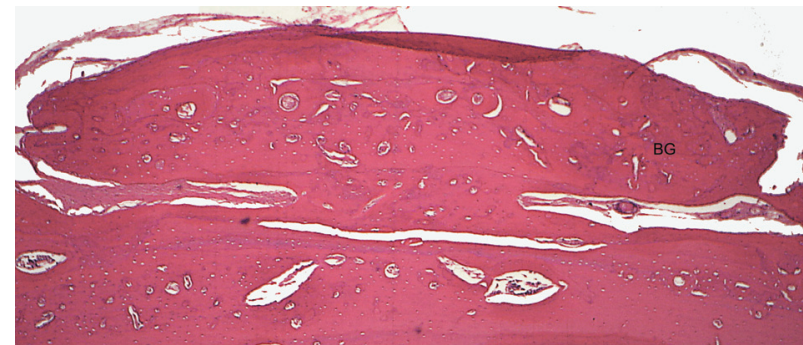

Figure 3- Group I - 30 days: Bone graft (BG) incorporated to the recipient site. New bone formation at the interface observed only at the graft central region, where the extremities remained filled by fibrous connective tissue (hematoxylin-eosin - Original 100x)

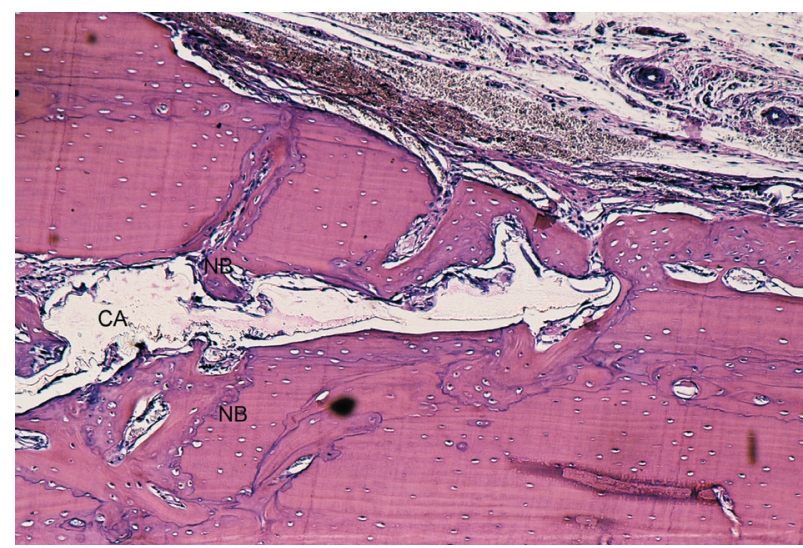

Figure 4- Group II - 30 days: Underneath, bone graft is linked to the recipient site only in the graft margin. Areas of new bone formation (BN) are observed in the internal surfaces of the grafts and in the recipient site. A space filled by a high amount of cyanoacrylate (CA) remains between the graft and the recipient site with a discrete inflammatory infiltrate (hematoxylin-eosin - Original 63x)

in most of the animals, this union could not be identified, because the region was filled with a lymphocyte-type inflammatory infiltrate, some blood vessels and several collagen fibers that maintained continuity with the capsule collagen fibers. Discrete areas of new bone formation were observed in the internal surfaces of the grafts, surfaces that were in contact with the CA. More deeply, between the graft and the recipient site, a space filled with a great amount of CA was observed. In several areas, multinucleate cells could be identified, mainly in the regions adjacent to the graft proximal surface (Figure 4). Few areas of newly formed bone were observed in this space until the time period studied. Regarding the recipient site, resorption areas and new bone formation areas could be identified in some of the specimens (Figure 5).

\section{Histometric and statistical results}

The mean bone graft sizes (in pixels) were $319,865( \pm 21,611)$ and $302,268( \pm 18,099)$ for

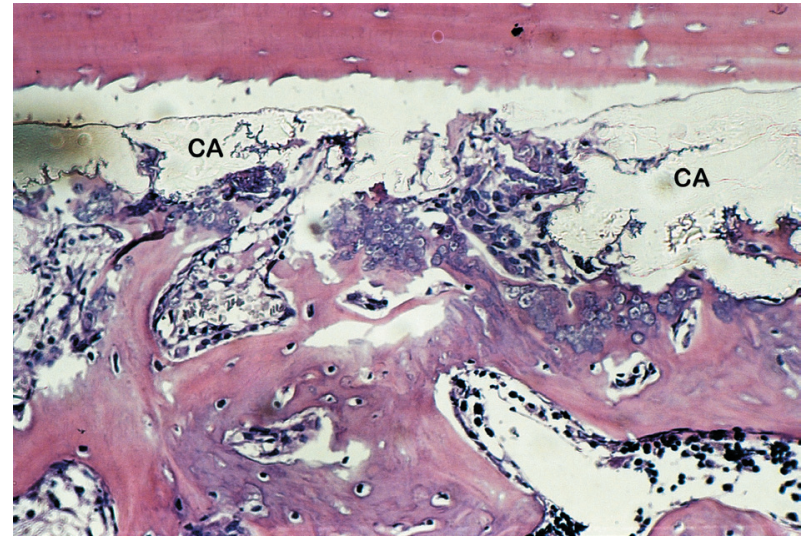

Figure 5- Group II - 30 days: New bone formation observed between the bone graft and the recipient site, in contact with the cyanoacrylate (CA) (hematoxylin-eosin - Original 160x)

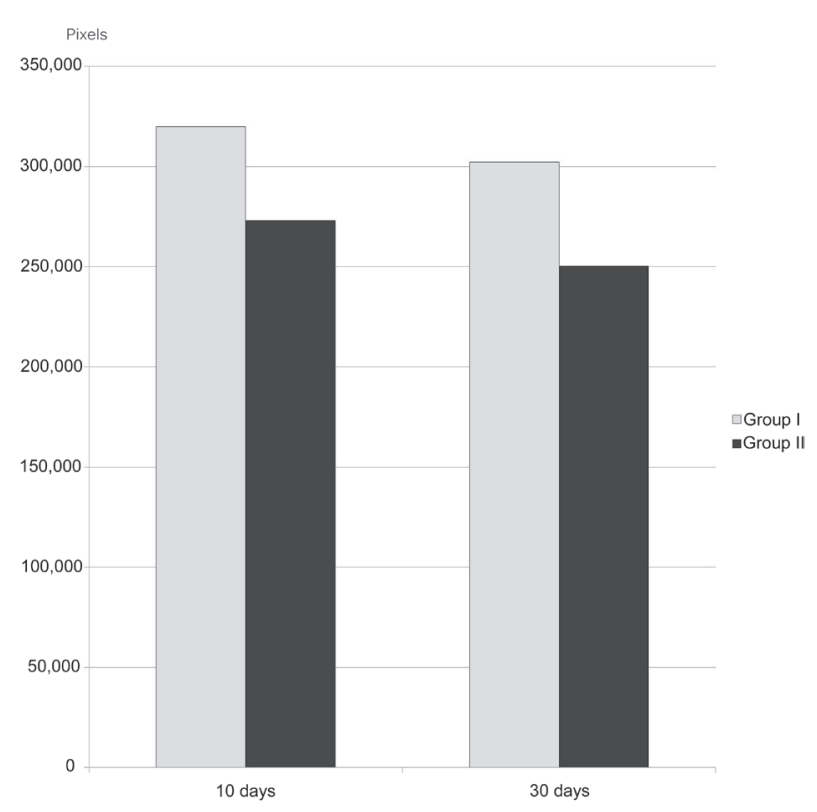

Figure 6- Area of the bone graft fragment in Groups I and II at 10 and 30 days

Group I at 10 and 30 days, respectively, and $273,149( \pm 19,178)$ and $250,391( \pm 25,127)$ for Group II at 10 and 30 days, respectively (Figure $6)$. In the statistical analysis, when both results from 10 and 30 days were compared, there was no statistically significant difference between Groups I and II $(p<0.05)$.

\section{DISCUSSION}

Graft fixation has great importance in the graft resorption decrease, once the volume loss is variable and inconstant. According to Lin, et al. ${ }^{17}$ (1990), the screwed internal rigid fixation enhances the life time of the onlay bone graft, decreasing its resorption when compared to the graft that is not fixed or stabilized by steel wire, mainly in great mobility areas. In the present investigation, 
it was not possible to use titanium screw for the graft fixation because the thin rat parietal bone makes impracticable its use. Thus, bone fragments fixed with the adhesive were compared to a group where the graft remained only juxtaposed to the recipient site.

The partial graft resorption is a natural process during its remodeling stage; however, the presence of inflammatory reaction or micromovements tends to accelerate and intensify this process ${ }^{17}$. It is important to emphasize that the bone graft at rat calvaria, as proposed in the experimental model of the present study, is not subjected to many movements; it is maintained in position and becomes properly incorporated to the recipient site, as observed in the control group at 10 and 30 days. Differently from the calvaria, in the mouth, the constant movements of the muscles and food, makes essential the fixation of the bone graft blocks. Graft stability is essential for the occurrence of revascularization and graft incorporation ${ }^{17,20}$.

According to clinical observations, the technique for using the adhesive was very simple, and, mechanically, the adhesive promoted a good adhesion of the graft to the recipient site. This was demonstrated by the fact that the bone fragment remained stable in both studied periods, confirming the good adhesive capacity of the ethyl-CA, which has been shown in previous studies ${ }^{11,23,27}$.

It has been reported that the smaller the ester chain, the higher its histotoxicity ${ }^{10}$. However, regarding the inflammatory reaction provided by the adhesive, it was observed to be higher at 10 days. At 30 days, a low intensity inflammation exhibited foreign body-type multinucleate cells in areas adjacent to the CA fragments. These findings indicate that the intense inflammatory reaction, produced by the material, has a short duration. According to Celik, et al. ${ }^{7}$ (1991), the inflammation is caused by a reaction dependent on tissue oxygen, explained by the transformation of the cellular membrane polyunsaturated fatty acids into hydroperoxide lipids, which increases the metabolism of the local arachidonic acid, unleashing the synthesis of tromboxane and prostaglandin.

There are few studies in vivo on CA behavior in the bone tissue. Clinical and experimental studies have demonstrated the adhesive efficacy to produce a stable union of bone segments ${ }^{1,8,12,14,16,27}$, however, the histological still remain not conclusive. Saska, et al. ${ }^{23}$ (2006), in a histomorphometric study utilizing rabbits as experimental models, fixed autogenous graft fragments in the calvaria with ethyl-CA adhesive. The results showed a discrete inflammatory infiltrate only at the first 15 postoperative days, which had totally receded at the posterior periods. In the present study, in fact, it was observed a decrease in the inflammatory intensity. However, the persistence of a discrete lymphocyte infiltrate associated with the presence of multinucleated cells, especially at the graft margins where the connective tissue was in direct contact with the adhesive, allow us to suggest that the material, though well tolerated, did not behave in a biocompatible way.

Similarly to the results of Saska, et al. ${ }^{23}$ (2006), our findings showed that the physical presence of ethyl-CA affected new bone formation. When CA fragments were suffering phagocytosis, granulation tissues containing fibroblasts, newly formed blood vessels and lymphocyte-type inflammatory infiltrate, were proliferating in the area. The formation of osseous trabeculae occurred after this migration, showing that the material did not have an osteoconductive or osteoinductive behavior, because it hampered the immediate new bone formation and graft incorporation to the recipient site. This fact, associated with the persistence of the discrete inflammatory process could explain the higher graft resorption observed at both 10 and 30 postoperative days.

Polymer degradation would be necessary for a complete repair process, providing results similar to those provided by the conventional internal rigid fixation. However, as a great amount of CA was still observed in the graft/recipient site interface, further studies with longer experimental periods are suggested to determine the total bone filling of the area and the maintenance or not of the graft bone size.

\section{CONCLUSION}

According to the methodology employed in this study, it was possible to conclude that, although allowing the maintenance and stability of the graft fragment at 30 days, the permanence of adhesive at the bone/graft interface did not allow graft incorporation to the recipient site, producing a low intensity but persistent local inflammatory reaction.

\section{REFERENCES}

1- Ahn DK, Sims CD, Randolph MA, O'Connor D, Butler PE, Amarante MTJ, et al. Craniofacial skeletal fixation using biodegradable plates and cyanoacrylate glue. Plast Reconstr Surg. 1997;99:1508-15.

2- Alkan S, Dadaş B, Celik D, Coskun BU, Yilmaz F, Başak T. The efficacy of N-2-butyl cyanoacrylate in the fixation of nasal septum to the anterior nasal spine in rabbits: experimental study. Eur Arch Otorhinolaryngol. 2007;264:1425-30

3- Amarante MTJ, Constantinescu MA, O'Connor D, Yaremchuk MJ. Cyanoacrylate fixation of the craniofacial skeleton: an experimental study. Plast Reconst Surg. 1995;95:639-46.

4- Blay A, Tunchel S, Sendyk WR. Viability of autogenous bone grafts obtained by using bone collectors: histological and microbiological study. Pesqui Odontol Bras. 2003;17:234-40. 
5- Boyne PJ, Lynch SE, Genco RJ, Marx RE. Studies of the surgical application of osteoconductive and osteoinductive materials. In: Lynch SE, Genco R, Marx R. Tissue engineering: applications in maxillofacial surgery and periodontics. Chicago: Quitessence Publishing; 1999.

6- Bruns TB, Simon HK, McLario DJ, Sullivan KM, Wood RJ, Anand $\mathrm{KJ}$. Laceration repair using a tissue adhesive in a children's emergency department. Pediatrics. 1996;98:673-5.

7- Celik H, Caner H, Tahta K, Ozcan OE, Erbengi A, Onol B. Nonsuture closure of arterial defect by vein graft using isobutyl-2cyanoacrylate as a tissue adhesive. J Neurosurg Sci. 1991;35:837.

8- Dadaş B, Alkan S, Cifci M, Başak T. Treatment of tripod fracture of zygomatic bone by N-2-butyl cyanoacrylate glue fixation, and its effects on the tissues. Eur Arch Otorhinolaryngol. 2007;264:53944.

9- Eaglstein WH, Sullivan T. Cyanoacrylates for skin closure. Dermatol Clin. 2005;23:193-8

10- Farion KJ, Osmond MH, Hartling L, Russell KF, Klassen TP,

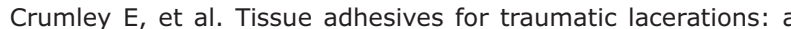
systematic review of randomized controlled trials. Acad Emerg Med. 2003;10:110-8.

11- García-Páez JM, Jorger-Herrero E, Rocha A, Maestro M, Castillo-Olivares JL, Millan I, et al. Comparative study of the mechanical behavior of a cyanoacrylate and a bioadhesive. J Mater Sci Mater Med. 2004;15:109-15.

12- Gonzalez E, Orta J, Quero C, Niemshik L, Galera R, Onay D, et al. Ethyl-2-cyanoacrylate fixation of the cranial bone flap after craniotomy. Surg Neurol. 2000;53:288-9.

13- Gosain AK, Lyon VB, Plastic Surgery Educational Foundation DATA Committee. The current status of tissue glues: part II. For adhesion of soft tissues. Plast Reconstr Surg. 2002;110:1581-4. 14- Gosain AK, Plastic Surgery Educational Foundation DATA Committee. The current status of tissue glues: I. For bone fixation. Plast Reconstr Surg. 2002;109:2581-3.

15- Howell JM, Bresnahan KA, Stair TO, Dhindsa HS, Edwards BA. Comparison of effects of suture and cyanoacrylate tissue adhesive on bacterial counts in contaminated lacerations. Antimicrob Agents Chemother. 1995;39:559-60.
16- Kim YO. Use of cyanoacrylate in facial bone fractures. ] Craniofac Surg. 1997; 8:229-34.

17- Lin KY, Bartlett SP, Yaremchuk MD, Fallon M, Grossman RF, Whitaker LA. The effect of rigid fixation on the survival of onlay bone graft: an experimental study. Plast Reconst Surg. 1990;86:449-56.

18- Lumsden AB, Heyman ER, Closure Medical Surgical Sealant Study Group. Prospective randomized study evaluating an absorbable cyanoacrylate for use in vascular reconstructions. J Vasc Surg. 2006;44:1002-9.

19- Macedo NL, Macedo LG, Matuda FS, Ouchi SM, Monteiro AS, Carvalho YR. Guided bone regeneration with subperiosteal implants of PTFE and hydroxyapatite physical barriers in rats. Braz Dent J. 2003;14:119-24.

20- Misch CE. Aumento do osso para inserção do implante: soluções para o enxerto ósseo. In: Misch CE. Implantes dentários contemporâneos. São Paulo: Ed. Santos; 2000. p. 451-65.

21- Pérez M, Fernández I, Marquez D, Bretaña RMG. Use of n-butyl2-cyanoacrylate in oral surgery: biological and clinical evaluation. Artif Organs. 2000;24:241-3.

22- Quinn J, Wells G, Sutcliffe T, Jarmuske M, Maw J, Stiell I, et al. A randomized trial comparing octylcyanoacrylate tissue adhesive and sutures in the management of lacerations. JAMA. 1997;277:1527-30.

23- Saska S, Hochuli-Vieira E, Minarelli-Gaspar AM, Gabrielli MF, Capela MV, Gabrielli MA. Fixation of autogenous bone grafts with ethyl-cyanoacrylate glue or titanium screws in the calvaria of rabbits. Int J Oral Maxillofac Surg. 2009;38:180-6.

24- Shermak MA, Wong L, Inque N, Crain BJ, Im MJ. Chao EYS, et al. Fixation of the craniofacial skeleton with butyl-2-cyanoacrylate and its effect on histotoxicity and healing. Plast Reconst Surg. 1998; 102:309-18.

25- Simon HK, McLario DJ, Bruns TB, Zempsky WT, Wood RJ, Sullivan KM. Long-term appearance of lacerations repaired using a tissue adhesive. Pediatrics. 1997;99:193-5.

26- Suuronen R. Biodegradable fracture-fixation devices in maxillofacial surgery. Int J Oral Maxillofac Surg. 1993;22:50-7. 27- Yilmaz C, Kuyutar F. Fixation of a talar osteochondral fracture with cyanoacrylate glue. Arthroscopy. 2005;21:1009. 